\title{
EXPERIÊNCIA DOCENTE COM APRENDIZAGEM SIGNIFICATIVA EM ETEC
}

\author{
Daniela Brugnaro Massari Sanches ${ }^{1}$ \\ Denise Tieko Uemura ${ }^{2}$ \\ Fernanda Cassiolato Marti Sguassábia ${ }^{3}$ \\ Samara Pereira Garcia ${ }^{4}$
}

\begin{abstract}
A aprendizagem significativa é o processo, por excelência, para adquirir e armazenar vasta quantidade de ideias e informações representadas em qualquer campo de conhecimento. (AUSUBEL, 1963, p. 58)

Segundo Moura e Barbosa (2011, p. 55), aprendizagem significativa ocorre quando:

O aluno interage com o assunto em estudo - ouvindo, falando, perguntando, discutindo, fazendo e ensinando - sendo estimulado a construir o conhecimento ao invés de recebê-lo de forma passiva do professor. Em um ambiente de aprendizagem ativa, o professor atua como orientador, supervisor, facilitador do processo de aprendizagem, e não apenas como fonte única de informação e conhecimento.
\end{abstract}

O processo de aprendizagem não pode estar separado da interação, das emoções e das sensações que provocam o desejo por compartilhar o que se aprende. O conhecimento é atingido por caminhos delineados por trocas, interferências, quando necessárias, e um planejamento flexibilizado e também interdisciplinar.

Nesse sentido, a iniciativa de escrever nossos relatos com abordagem em aprendizagem significativa surgiu durante o curso de capacitação docente propiciado pelo Centro Paula Souza e intitulado: "Da prática docente ao artigo científico: caminhos do professor intelectual". Aqui formado por quatro professoras de Etec, de diferentes áreas do conhecimento, atuando com alunos do Ensino Médio e Técnico, com distintas experiências e que buscam pensar as diversas correntes ideológicas educacionais vigentes. Assim, a partir das anotações e registros das práticas desenvolvidas em aulas, o objetivo é relatar nossas experiências e compartilhá-las a fim de mostrar que há diferentes caminhos e formas para se atingirem os resultados por meio da aprendizagem significativa.

\section{O uso das TICS (tecnologia de informação e comunicação) nas aulas de língua estrangeira moderna, inglês e comunicação profissional}

Atualmente, é notória a utilização cada vez maior das diferentes tecnologias, como tablets, smartphones, smart TVs pelo público jovem. Entretanto, o chamariz desses aparatos eletrônicos é a internet. Por meio desta, abre-se um leque de acesso: redes sociais (Facebook, Instagram, Twitter), aplicativos (apps), lojas online entre outros. Surge, então, aquela pergunta: por que não utilizar essas tecnologias na sala de aula e tornar o conteúdo a ser aprendido mais atrativo, dinâmico e resolver problemas identificados no processo de ensino-aprendizagem?

Uma das dificuldades identificadas no curso do $1^{\circ}$ ano do Ensino Técnico de Nutrição e Dietética Integrado ao Ensino Médio (Etim) da Etec Trajano Camargo (Limeira) foi a questão

\footnotetext{
${ }^{1}$ E-mail: daniela.sanches@etec.sp.gov.br.

${ }^{2}$ E-mail: denise.uemura01@etec.sp.gov.br.

${ }^{3}$ E-mail: fernanda.sguassabia@etec.sp.gov.br.

${ }^{4}$ E-mail: samara.garcia3@etec.sp.gov.br.
} 
da deficiência do vocabulário técnico, ou seja, aquelas palavras específicas que são pertencentes à área de estudo do curso, como rotulagem nutricional, entre outros, tanto em língua materna quanto em inglês. De acordo com Leffa (2000), "língua não é só léxico, mas o léxico é o elemento que melhor a caracteriza e a distingue das outras."

Como tentativa de solucionar esse problema, foi proposto aos discentes a criação de um "Picture dictionary" com o tema alimentos. Para a execução deste, foi adotado como procedimento metodológico o seminário, o qual também possibilitou aos alunos trabalharem em grupo desenvolvendo a socialização, o aprofundamento dos conhecimentos e a autonomia. Em seguida, iniciou-se o trabalho de pesquisa com o uso das TICs, buscando privilegiar a construção do conhecimento e um aprendizado significativo. O resultado dos trabalhos foi compilado e apresentado em PowerPoint para a sala pelos alunos, após correção da professora. Vale dizer que os critérios de avaliação foram previamente explicitados para a classe antes da execução da atividade.

Por fim, foi aplicado aos alunos um exercício que envolvia leitura e compreensão de textos na área de nutrição, objetivando a retomada de vocabulários específicos aprendidos anteriormente. Vale lembrar que o conhecimento é construído individual e socialmente, a partir de interações com o ambiente, ou seja, que este não deve ser transmitido diretamente.

Logo, por meio da observação direta, notou-se que os alunos estavam muito mais tranquilos para realizar a leitura e resolução dos exercícios quando comparados a turmas anteriores, para as quais não houve aprofundamento do vocabulário específico antes da prática de leitura. Esses dados também foram evidenciados e confirmados por meio do questionário aplicado aos alunos, nos quais estes relataram sentimentos de confiança e segurança, ou seja, entende-se que se encontram aptos a realizar tal competência.

\section{Projeto Arte e Literatura, realizado com alunos da $3^{\text {a }}$ série do ensino médio}

Os alunos desenvolveram um trabalho com base nas vanguardas artísticas europeias surgidas no século XX: Futurismo, Cubismo, Expressionismo, Dadaísmo e Surrealismo, as quais trouxeram um novo olhar para a produção artística, como também grandes mudanças ao cenário artístico e literário brasileiro do início do século XX.

Para trazer às aulas a singularidade desse período de transformações, o objetivo foi o de buscar, em metodologias diversificadas, a aprendizagem significativa cabível ao assunto da aula, além de relacionar teoria e prática. Com esse ponto de partida, foi proposto aos discentes um trabalho de pesquisa e apresentação sobre as vanguardas artísticas sob a forma de exposição artística e interpretação cênica amadora de um dos artistas selecionados previamente pela docente. Essa proposta traria motivação para a pesquisa, favorecendo o trabalho em equipe, o relacionamento interpessoal, a preocupação na escolha das linguagens verbal e não-verbal e, finalmente, o estudo relacionado ao prazer, proporcionando a aprendizagem significativa. Dessa forma, o trabalho proposto respeitou as seguintes orientações: divisão dos alunos em cinco grupos, cada qual responsável por uma das vanguardas. As obras a serem apresentadas na exposição eram de artistas de cada vanguarda, outras de artistas brasileiros influenciados pelas vanguardas europeias e, por fim, poemas relacionados às vanguardas.

Apoiando-se nesse material, os alunos precisaram pesquisar os princípios e as características de cada um dos movimentos artísticos para poder relacioná-los obras artísticas e literárias, explicando-as. Ao menos um integrante de cada grupo deveria escolher um dos artistas e interpretá-lo, através da busca de sua história de vida, nacionalidade, vestimentas, manias, produções, enfim, tudo o que o ajudasse a compor a personagem para a exposição, 
trazendo à tona curiosidades ou fatos que considerassem interessantes para serem compartilhados com os colegas. Os poemas foram interpretados de forma a dar vida ao texto poético e analisados tendo por base o movimento artístico de vanguarda.

O resultado foi fascinante: além do que fora solicitado pela professora, os alunos criaram situações para contextualizar a interpretação do artista escolhido, produziram cópias de esculturas artísticas e mostraram domínio dos conhecimentos, empatia e sintonia com os membros do grupo. A satisfação dos discentes se tornou evidente. A atividade favoreceu o processo de ensino-aprendizagem, em que ambos os lados, professor e alunos, aprendem e ensinam, favorecendo um ambiente de troca de experiências, de conhecimentos e de afetividade, portanto, favorável ao saber (FREIRE, 2002, p. 29).

\section{Pesquisa com alunos na ETEC Prefeito Braz Paschoalin}

A pesquisa histórica para o aluno do Ensino Médio Técnico e, com frequência, também para o professor, parece não fazer sentido, quando a preocupação com a formação para o mercado de trabalho e o vestibular se fazem mais atraentes. Então, como atrair o aluno? Tentando encontrar sentido nesse movimento, surge o projeto de pesquisa de história no ano de 2016, que tem, adicionalmente, a perspectiva de envolver a comunidade escolar em uma rede de preservação e conservação de um patrimônio público, tão carregado de significados para a cidade. $\mathrm{O}$ historiador Marc Bloch gostava de citar um provérbio árabe: "O homem se parece mais com o seu tempo do que com seu pai”. Assim, pensar a pesquisa histórica no contexto educativo é pensar como aproximar o aluno do fazer, do despertar para o agir sobre a história do seu tempo e compreender a relação passado - presente.

O grupo, formado após um convite para uma primeira reunião, estabeleceu-se apenas com alunos do $2^{\circ}$ ano do Ensino Técnico Integrado ao Médio, mas logo percebeu-se que poderiam ser incluídos alunos do $1^{\circ}$ ano. Então, chegou-se a onze alunos e dois professores, ambos da disciplina de História. A primeira etapa do projeto, voltada para sensibilização, contou com análise da própria certidão de nascimento, leitura e discussão de texto e entrega de pasta com alguns materiais básicos para organização da pesquisa.

$\mathrm{Na}$ segunda etapa, realizaram-se buscas por informações para saber quais seriam as fontes: familiares, sites, instituições públicas e privadas; ocorreu a visita ao Arquivo do Estado de São Paulo e o grupo decidiu quais seriam os próximos passos da pesquisa. Assim, o grupo foi subdividido para atender às demandas surgidas a partir das informações, levando à reorganização de algumas ações. Muitas informações foram colhidas, algumas soltas e com lacunas a serem preenchidas, mas apontando para a hipótese inicial, o prédio sempre teve vocação para abrigar instituições ou departamentos públicos voltados para o ensino. Apropriarse do conhecimento e serem reconhecidos como os alunos que fazem parte do grupo de pesquisa tornou-os diferentes, não só com relação à dinâmica da própria escola, mas em relação aos professores. Em alguns encontros, eles foram surpreendidos positivamente, partilhando momentos que, além do aprendizado escolar, resultaram em conversas descontraídas e carregadas de significados e informações.

Nesse sentido, considerando a relação pesquisa-ensino-aprendizagem, o projeto possibilita o "fazer história" quando envolve o aluno e também o professor, permite compreender que este fazer no contexto educacional, além de estar carregado de outros significados, outros sentidos e outras aprendizagens, como a dimensão básica de cidadania contida ali: a aprendizagem significativa. 


\section{Experiência de segurança com os alunos do curso técnico}

Quando iniciamos a aula, conversamos com os alunos sobre que tipos de situações já passaram e onde necessitaram de mais conhecimentos em segurança. Com um vasto leque de idades (de 17 a 50 anos), o curso citado traz um público diversificado em uma mesma sala de aula, cada aluno demonstra um pouco do seu conhecimento de vida, suas experiências de trabalho, trazendo-as como referências do tema abordado: equipamentos de segurança, afastamentos, acidentes no trabalho, CIPA e suas funções, entre outros assuntos relacionados.

Como utilizar e organizar todas essas experiências e torná-las importantes componentes na matriz curricular das disciplinas do curso? Como utilizar suas situações-problema como situações de aprendizagem? Estas são informações essenciais para a aprendizagem significativa. Uma aula significativa de primeiros socorros deve apresentar como fazer o atendimento de urgência e emergência? Todos sabem como fazer, mas será que está certo? Quais legislações são aplicadas? A busca do conhecimento dos procedimentos corretos intensifica a participação dos alunos? Na Etec Ferraz de Vasconcelos, sim, pois confeccionamos bonecos para a prática da massagem cardíaca, produzimos talas de papelão para a imobilização de membros e utilizamos garrafas pet para a construção de apoio cervical de pescoço. Todos participam e ampliam com isso os conhecimentos de primeiros socorros inclusive em questões como curativos, queimaduras e suturas.

Dessa forma, foi possível perceber que, durante a aplicação da aula e sua prática, conseguimos avaliar a aprendizagem do conteúdo proposto e ressignificar o tema para o evento voltado à comunidade escolar: a SIPAT Escolar, para o Treinamento de Brigada de Incêndio a docentes e discentes. $\mathrm{O}$ evento tornou-se ainda mais significativo, pois todas essas atividades foram ministradas pelos alunos, com a interação dos docentes, coordenação de área e coordenação pedagógica.

\section{O que podemos concluir...}

O desempenho em sala de aula, pode ser mensurado de diversas maneiras, ainda que o instrumento de avaliação mais utilizado pelos professores seja a escrita, é necessário observar se a compreensão dos conteúdos e o interesse pelos temas propostos podem ser atingidos por meio de práticas que representem uma aprendizagem significativa e que envolvam prazerosa e até gradativamente os alunos nessa relação, partindo da condição que a aprendizagem é ativa.

As experiências apresentadas neste texto não configuram receitas, mas contribuem com o vasto repertório de ações para quem busca novos olhares em relação à aprendizagem. Contudo, nas escolas em que foram aplicadas, demonstraram ser significativas ao serem realizadas, possibilitando interação e protagonismo.

\section{Referências}

AUSUBEL, D. P. The Psychology of Meaningful Verbal Learning. New York: Grune and Stratton, 1963.

BLOCH, M. In: CHESNEAUX, Jean. Devemos fazer tábula rasa do passado? Sobre a história e os historiadores. São Paulo: Ática, 1995.

CUNHA, R. B.; PRADO, G. V. T. A Produção do Conhecimento e Saberes do/a professor/a pesquisador/a. 2005. Disponível em: 〈http://www.scielo.br/pdf/er/n30/a16n30.pdf $>$. Acesso em 29 out. 2016. 
FREIRE, Paulo. Pedagogia da Autonomia: saberes necessários à prática educativa. São Paulo: Paz e Terra, 2002.

GODARD, J. L. “Fragments Du Discours D’um Amoreux Des Mots”. In: JOLY, M. Introdução a Análise da Imagem. São Paulo: Editora Papirus, 1996.

LEFFA, V. Disponível em: 〈http://www.leffa.pro.br/textos/trabalho/vocabulario.pdf >. Acesso em 21 abr. 2017.

MOREIRA, M. A. Aprendizagem significativa. Brasília: Editora Universidade de Brasília, 1999. . Teorias de Aprendizagem. São Paulo: Editora Pedagógica e Universitária Ltda, 1999. . “Aprendizagem significativa: um conceito subjacente". In: Aprendizagem Significativa em Revista (Meaningful Learning) - v. 1 (3), 2011. Disponível em: $<$ http://www.if.ufrgs.br/asr/artigos/Artigo_ID16/v1_n3 a2011.pdf $>$. Acesso em 28 out. 2016.

MOURA, D. G.; BARBOSA, E. F. Trabalhando com projetos - Planejamento e gestão de projetos educacionais. Petrópolis: Editora Vozes, 2011.

PAIVA, Vera Lúcia Menezes de Oliveira. Ensino de língua inglesa no Ensino Médio: teoria e prática. São Paulo: Edições SM, 2012. 